\title{
Microbiological Examination of Animal Fertilizer and effects of associated pathogens on the health of Farmers and Farm Animals
}

\author{
D. O. Akeredolu ${ }^{1,2 *}$ and AO. Ekundayo ${ }^{2}$ \\ ${ }^{1}$ Department of Microbiology, University of Benin, Benin-City, Edo State
}

${ }^{2}$ Ambrose Alli University, Ekpoma, Edo State

Received: 12 August, 2017; Accepted: 09 September, 2017; Published: 25 September, 2017

*Corresponding author: D. O. Akeredolu, Department of Microbiology, University of Benin, Benin-City, Edo State; E-mail: dennisakeredolu@ gmail.com

\begin{abstract}
The aim of this study was to determine the microbial load and examine the individual types of microorganisms found in animal fertilizer. A microbiological analysis of animal fertilizer was carried out. The samples were collected from commercially prepared animal and poultry fertilizer. The presence of bacteria and fungi were detected. The bacteria spp isolated were Salmonella spp, Staphylococcus aureus, Listeria monocytogenes, Bacillus sp., Proteus sp., Escherichia coli, Klebsiella spp. and Enterobacter spp. while the fungal isolates were Aspergillus niger, Aspergillus flavus, Penicillium spp. and Mucor spp. The microbial burden of animal fertilizer analysed was high with an average of $7.2 \times 10^{6} \mathrm{cfu} / \mathrm{g}$. some of these organisms such as Salmonella sp., Listeria monocytogenes, Escherichia coli and Aspergillus and Penicillium spp. have been associated with pathogenic conditions and are likely to cause salmonellosis, listeriosis, gastroinstinal trac infection, and diseases of the lungs if not properly handled. Survival of these microorganisms in animal fertilizer is affected by the source, $\mathrm{pH}$, dry matter content, age, and chemical composition of the manure as well as microbial characteristics. The results of this study show that animal fertilizer contains very dangerous and harmful microorganisms which can cause ill-health to humans and other living organisms.
\end{abstract}

Keywords: Bacteria; Fungi; Animal fertilizer; Microbial load

\section{Introduction}

Animal fertilizer (manure) is a biologically active material, alive with bacteria and other microorganisms that depend on the energy contained in animal fertilizer. Animal manure is an energy-rich feedstuff produced as animal waste that is filled with potentially active microorganisms (1). The use of animal fertilizer energy by microorganisms is a natural process of decomposition. Except in extreme cases of cold, ph, or lack of water, biological decomposition is inevitable. By storing, handling, or treating manure in various ways, farmers can control the by-products produced by this biological activity. This is important to a farmer desiring to manage nutrients, control or create a marketable product (1). Maintaining profitability in farming while protecting quality and the health of humans and animals is one of the challenges that farmers face. Run-off of sediments, pesticides and nutrients such as phosphorus and nitrogen has been considered the greatest environmental threats to water quality posed by animal agriculture (2). When considering the problem of pathogen transmission through animal fertilizer it is important to recognize that animal fertilizer, which consist of animal excreta (feces and urine), beddings, and dilution water, blood, vagina, mammary gland, skin, and placenta. Microbes in these secretions, as well as those in the excreta, can potentially accumulate on the barn floor. Unless the manure is handled appropriately, the pathogens may infect other animals or humans (Strauch and Ballarini, 1994). These microorganisms will use the energy in manure, causing the manure to change. The challenge of biological manipulation is to manage the environment in which these changes take place in order to produce (or not to produce) specific by-products (1). Before the widespread use of chemical fertilizers, animal fertilizers (manures) were used as a primary source of nutrients in crop production. In addition to supplying plant nutrients to the soil, manure also improves soil health by increasing soil organic matter and promoting beneficial organisms. Incorporating manure by improving soil structure (3). Animal manure contains all the essential micro and macro elements required for plant growth. Land application of animal manure increases soil organic matter and improves a number of soil properties including soil tilth, water holding capacity, oxygen content, and soil fertility. It also reduces nutrient leaching, and increases water infiltration rates, reduces nutrient leaching, and increases crop yields. In general, results of research indicate that manure is a valuable bio-resource that should be utilized (Pratt, 1982, 4,5).

Livestock manure contains a broader range of nutrients than most commercial fertilizers. This is because a large portion of the plant nutrients initially ingested by the animals, generally $80 \%$ of the phosphorus, $90 \%$ of the potassium and $75 \%$ of the nitrogen are still present in the manure (5). Nutrient availability, however, is determined by the manure handling system, as well as by climate and soil characteristics. Nutrient values also vary 
with different types of livestock and the animal feed ratios, which vary with the season. Generally, poultry manure tends to be high in Nitrogen $(\mathrm{N})$ and phosphorus $(\mathrm{P})$, while dairy manure tends to be high in Potassium (K) (6). The actual nutrient value of manure from a particular operation will differ considerably with the method of collection, storage facilities, and species of animal (Zhang, 2005). Nutrients in waste may be lost or converted to other forms during treatment or storage and handling, affecting their availability for use by growing plants. The type of animal housing system and/or waste handling method is known to affect the final nutrient composition of the waste (Zhang, 2005). Bedding and waste have a diluting effect on the final nutrient concentration of waste and result in less nutrient value per ton. In addition, the type of housing and waste handling system can decrease the final nutrient composition of waste materials. For instance, there can be considerable loss of nitrogen to the air, and there is potential for runoff and leaching when animal waste is exposed to weather conditions in an open lot system.

Manure application rates should be specific to the crops and soil, and applications should be scheduled to fit the farming operation and the season. The application rate should be carefully estimated because if it is excessive, it can cause pollution of surface and ground water, toxicity to livestock consuming the crops, and contribute to problems with plant growth. Application should also be timed to avoid spreading in winter and early spring; frozen ground and rainfall which may lead to run off and leaching of nutrients into water resources where they become pollutants (Peterson, 1995). Methods of application include a conventional beater-spreader, liquid tank wagon, large bore irrigation nozzle (for liquid), and/or a shovel and pitch fork. The "big-gun" sprinkler applications should be avoided because they offer the least accuracy and control when applying liquid manure to a specific area. Tank-type spreaders on the other hand, provide the most accuracy and control (Peterson, 1995). Manure (animal fertilizer) should be applied to flat land whenever possible and be incorporated into soil shortly after spreading to reduce loss of nitrogen. The rate of manure application should decrease as slope increase. Vegetative buffer strips at the base of the slope can prevent run off of nutrients on sloped land. Whenever manure is applied to land, it is important to keep good records of the data, amount applied, nutrient content, soil test results, weather as well as any other notes that would be helpful to have in the future. These records can be used to determine future application rates and also to provide documentation of application if questions or issues arise in the future (Peterson, 1995). Biological manipulation can be used to manage odor, nutrients, consistency, and stability of the treated manure product. For example, manure, combined with a carbon rich material such as sawdust and sufficient air, can be transformed into stable compost. On the other hand, by eliminating all air and adding heat, raw manure that contains little bedding can be transform into biogas and a low-odor, nutrient rich liquefied, stable effluent. Biological manipulation involves providing the proper "diet" and environment for the specific microorganisms that will use the manure energy (1).
The commission of the European Communities identified reportable bacteria that are of particular concern for animal and human health (7) included in their list are Salmonella spp, Escherichia coli, Bacillus anthracis, Mycobacterium spp, Brucella spp,, (especially Brucella abortus), Leptospira spp,, Chlamydia spp, and Rickettsia spp.. In addition to these organisms, other potential bacterial pathogens in manure include; Listeria monocytogenes, Yersinia enterocolitica, Clostridium perfringes, and Klebsiella spp, (8). To assess the threat posed by different microorganisms in manure, bacteria survival in manure as it is usually handled on farms must be evaluated. Survival is affected by the source, $\mathrm{pH}$, dry matter content, age, and chemical composition of the manure as well as by microbial characteristics. Manure that is well mixed with bedding is more likely to undergo aerobic fermentation with accompanying temperature increases than in slurry with minimal amounts of beddings. Problems are also posed by viruses, which are obligate intracellular parasites (Snowdon et al., 1989; Strauch, 1991) that often have limited host range. Giardia spp, and Cryptosporidium parvum are protozoans that cause severe diarrhea in both animals and humans. In 1993 to 1994, one third of the outbreaks associated with drinking water for which the causative agent was identified were due to these two pathogens (9). Cryptosporidium parvum, first identified in 1975 (Rose, 1990). In healthy mature animal (including humans), the infections caused by both Giardia and C. parvum are usually self limiting and although they cause significant discomfort, do not pose serious long-term health risks. Infected animals may shed as many as $1.0 \times 10^{9}$ oocysts daily for 1 to 12 days (Ridley and Olsen, 1991). Farmers, animal handlers, veterinarians, others who work with animals are more likely to be infected than the general population (2). Whenever manure is applied to food crops, safety precautions should be taken to avoid contamination that might result in human illness. The pathogens of most concern that can be found in livestock manure are E. coli and Samonella sp. to avoid the risk of contamination, fresh manure should not to be applied within 60 days of harvesting food crops (10). Xylanases are used in the pretreatment of forage crops to improve the digestibility of ruminant feeds and to facilitate composting along with glucanases, pectinases, cellulases, proteases, amylases, galactosidases, and lipases. Phytase is an enzyme that makes the phosphorus from phytin available for animal digestion. Up to now, phytase is increasingly used in animal feeds, science and technology related to this enzyme are rapidly evolved. The benefits of phytase are its double effects on reducing the use of expensive inorganic phosphorus in animal diets and the environment pollution from excessive manure phosphorus runoff. The aim of this study was to determine the microbial load and examine the individual types of microorganisms found in animal fertilizer and their possible pathogenic effects to farm animals and farmers.

\section{Materials and Methods \\ Collection of Samples and Media Preparation}

The samples were collected from commercially prepared animal/bird fertilizer. All glasswares were sterilized by heating at 
$160^{\circ} \mathrm{C}$ for 1 hour after washing them. This was done by the hot air oven. All plastics were washed and disinfected with formaldehyde. The following media were used during the course of study; Nutrient agar, MacConkey, Peptone water, Potato dextrose agar.

The Nutrient agar was prepared by dissolving $14 \mathrm{~g}$ in $500 \mathrm{ml}$ of distilled water and sterilized with pressure cooker at $121^{\circ} \mathrm{C}$ for 15 minutes. MacCokey agar was prepared by dissolving $24 \mathrm{~g}$ in $500 \mathrm{ml}$ of distilled water and sterilized at $121^{\circ} \mathrm{C}$ for 15 minutes with the pressure cooker. Peptone water was prepared by dissolving $7.5 \mathrm{~g}$ of powder in $500 \mathrm{ml}$ of distilled water and was sterilized with pressure cooker for 15 minutes at $121^{\circ} \mathrm{C}$.

\section{Sample Preparation and Culturing}

One gram of the animal/ bird dung fertilizer was weighed using a beam balance and introduced into one of the ten test tubes containing $9 \mathrm{ml}$ each of normal saline to form the stock solution of the sample. Using a sterile pipette, $1 \mathrm{ml}$ was taken from the stock to test tube II, from this, $1 \mathrm{ml}$ was taken from the II after shaking into test tube III. This procedure was repeated until a $10^{-10}$ dilution was obtained. The pour plate method was used to determine the appropriate dilution to be adopted. This was done by pouring molten nutrient agar on $1 \mathrm{ml}$ of sample. The plates were allowed to solidify and incubated at $37^{\circ} \mathrm{C}$ for 24 hours. After 24 hours, colonies from plate $10^{5} .10^{7}$, and $10^{9}$ dilution were countable while those of plates $10^{1}$ and $10^{3}$ were too many to be counted. The different colonies were purified by sub culturing to obtain discrete colonies by streaking on new plates containing Nutrient and MacConkey agar.

\section{Identification of Bacteria Isolates}

Identification was based on morphology, cultural and biochemical characteristics of the colonies.

Colonies having the same morphology were used to form slants, after Gram staining and other biochemical tests were carried out such as gram staining reaction, motility, catalyst test, indole test, sugar fermentation test, citrate test, oxidase test and coagulase test:

\section{Identification of Fungi}

With a sterile inoculation needle the fungus was removed from its pure culture on a grease free slide. It was teased out with the sterile needle and then stained with methylene blue. A cover slip was placed on the stained portion. It was then observed under the light microscope for cultural characteristics such as hyphae type, spores etc.

\section{Analysis of disease outbreak}

A health accessment was carried out for all farmers who were using the animal fertilizers. A questioner was developed to find out if there were any diseases out break as a result of the use of the animal fertilizers.

\section{Results}

The total viable bacterial count at $37^{\circ} \mathrm{C}$ for 24 hours was enumerated and had a mean count of $7.2 \times 10^{6} \mathrm{cfu} / \mathrm{g}$ (Table 1). Table 3 showed the biochemical characteristics and Gram reaction of the bacteria isolates. The following bacteria were isolated: Escherichia coli, Staphylococcus aureus, Bacillus spp, Proteus spp, Klebsiella spp, Listeria monocytogenes, Enterobacter spp and Salmonella spp. the following fungal isolates were identified and Characterized: Aspergillus niger, Aspergillus flavus, Penicillium species and Mucor species (Table 2).

\begin{tabular}{|c|c|c|c|}
\hline Samples & Dilution used & Colony count & $\begin{array}{l}\text { Mean bacteria } \\
\text { count }(\mathrm{cfu} / \mathrm{g})\end{array}$ \\
\hline $\begin{array}{l}\text { Commercially } \\
\text { prepared } \\
\text { animal/bird } \\
\text { dung fertilizer }\end{array}$ & $5-0 c t$ & 72 & $7.2 \times 106$ \\
\hline
\end{tabular}

\begin{tabular}{|c|c|c|}
\hline \multicolumn{2}{|c|}{ Table 2: Identification and Characterization of fungal isolates } \\
\hline Isolates & $\begin{array}{c}\text { Cultural and Morphological } \\
\text { characteristics }\end{array}$ & Fungi \\
\hline A & Light green fluffy with black spot & $\begin{array}{c}\text { Aspergillus } \\
\text { niger }\end{array}$ \\
\hline B & Thick green not widely spreading & $\begin{array}{c}\text { Aspergillus } \\
\text { flavus }\end{array}$ \\
\hline C & Center green surrounded with edges & Penicillium spp \\
\hline D & Black sporty growth with no rhizoids & Mucor spp \\
\hline
\end{tabular}

\section{Discussion}

This study reveals the presence of eight bacterial species and four fungal species. The bacterial species include; Escherichia coli, Staphylococcus aureus, Bacillus spp, Proteus spp, Klebsiella spp, Listeria monocytogenes, Enterobacter spp and Salmonella spp While the fungal species include; Aspergillus niger, Aspergillus flavus, Penicillium species and Mucor species. Past research has shown some of these bacteria isolates as potential bacterial pathogens in animal fertilizer. Work by Mawdsley et al, (5) reveals the presence of Listeria monocytogenes, Salmonella spp, Escherichia coli and Klebsiella spp in livestock waste. Dairy farms have been identified as reservoirs of E.coli (10) and Listeria monocytogenes lives naturally in plant and soil environments and poorly fermented silage often contains high numbers of Listeria monocytogenes (11). Animal fertilizer has been shown to contain Salmonella spp, even from the feces of apparently healthy animals (12). The gastro intestinal tracts of animals also harbor most of these organisms such as Enterobacter spp, Proteus spp, and Staphylococcus aureus. While Bacillus spp, are environment friendly because of their spores (11). The presence of these bacteria in animal fertilizer is a cause for public health concern, since these bacteria especially E. coli, Staphylococcus aureus, Bacillus spp, Salmonella spp and Listeria monocytogenes are known to be pathogenic. 


\begin{tabular}{|c|c|c|c|c|c|c|c|c|c|c|c|c|c|c|c|c|}
\hline 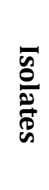 & 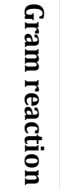 & 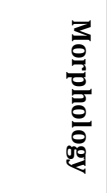 & 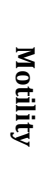 & 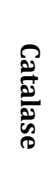 & $\frac{\bar{\partial}}{\frac{0}{0}}$ & 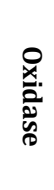 & 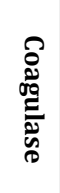 & 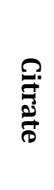 & 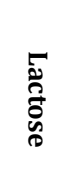 & 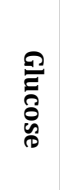 & 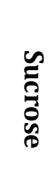 & 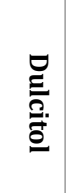 & 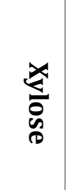 & 疍 & 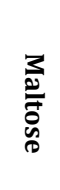 & Suspected organisms \\
\hline A & - & rods & + & + & - & - & - & + & A & A & - & \pm & - & + & + & Salmonella spp \\
\hline B & + & cocci & - & + & - & - & + & - & + & + & + & - & + & + & + & Staphylococcus aureus \\
\hline $\mathrm{C}$ & + & rods & + & + & - & - & - & - & + & + & \pm & - & + & - & + & Listeria monocytogenes \\
\hline D & - & rods & + & + & - & - & - & - & - & + & + & - & - & + & + & Bacillus spp \\
\hline $\mathrm{E}$ & - & rods & + & + & + & - & - & + & - & + & \pm & + & - & - & + & Proteus spp \\
\hline $\mathrm{F}$ & - & rods & + & - & + & - & - & - & $+\mathrm{G}$ & $+\mathrm{G}$ & + & - & - & + & + & Escherichia coli \\
\hline G & - & rods & - & + & - & - & - & + & + & + & + & ND & ND & + & + & Klebsiella pneumoniae \\
\hline $\mathrm{H}$ & - & rods & + & - & - & - & - & + & + & + & + & + & - & \pm & + & Enterobacter spp \\
\hline
\end{tabular}

From the observation made from this research work, moulds such as Aspergillus flavus, Aspergillus niger, Penicillium spp and Mucor spp were responsible for the decomposition of this animal fertilizer, since they are common fungi found in the environment. This shows that animal fertilizer contains an incredible amount of pathogenic microorganisms. The survival of these microorganisms in animal fertilizer is affected by the source, $\mathrm{pH}$, dry matter content, age, and chemical composition of the manure as well as the individual microbial characteristics. From of the health accessmet from the farmers, there was no significant disease out break as a result of the use of animal fertilizers. It could be that the farmers may not have reported acurrately on their questioners or that they have applied very good health safty measures while using the animal fertilizers. It is therefore very important to use hand gloves and other safty garjets while appling animal fertilzer to avoid microbial infection that are associated with animal fertilizer.

\section{Conclusion}

The results of this study show that animal fertilizer contains very dangerous and harmful microorganisms which can cause illhealth to humans and other living organisms if they get to source of easy intake like water. There should be proper management procedures taken to ensure that these animal fertilizers do not get to any source of drinking water or food. Before applying manure, it is important to have both the manure and the soil tested for nutrient content. Food safety considerations should be a priority when utilizing manure to fertilize food crops, especially fruits and vegetables and appropriate environmental safeguards, such as filter strips are to be used.

\section{References}

1. Leggett JA.1996. Biological Manipulation of Manure: getting what you want from animal manure. Department of Agriculture and Biological Engineering. College of Agriculture Sciences. Pennesylvania University Cooperative extension.

2. Mac Kenzie WR, Hoxie NJ, Proctor ME, Gradus MS, Blair KA, Peterson $\mathrm{DE}$, et al. A massive outbreak in Milwaukee of Cryptosporidium infection transmitted through the public water supply. N Engl J Med. 1994;331(3):161-167. Doi: 10.1056/NEJM199407213310304

3. Hermason, R. E. 1996. Manure Sampling For Nutrient Analysis with Worksheets for Calculating Fertilizer Values. WSU Extention Bulletin No.1819.

4. Araji A A, Stodick LD. "The Economic potential of feedlot wastes utilization in Agricultural production". Biological Manure. 1990;32(2):111-124. Doi:10.1016/0269-7483(90)90076-5

5. Cassman KG, Steiner R, Johnson AE. "Long Term Experiments and Productivity Indexes to Evaluate the Sustainability of Cropping System". In: Agricultural Sustainabilit: Economic, Environmental and Statistical Considerations. 1st edition, John Wiley and Son. 1995;348.

6. Brandy N, Ray W. The Nature and properties of soils. Prentice Hall, New Jersery. 1996:1-3. 
7. Kelly WR. Animal and animal health hazards associated with the utilization of animal effluents. EUR. 6009. Office. Publ. Eur. Commun. Luxembourg. 1978.

8. Mawdsley JL, Bardgett RD, Merry RJ, Pain BF, and Theodorou MK Pathogens in Livestock Waste, their Potential for movement through soil and environmental pollution. Appl Soil Ecol. 1995;2(1):1-15.Doi: 10.1016/0929-1393(94)00039-A

9. Kramer MH, Herwaldt B L, Craun GF, Calderon RL, Juranek DD Waterborne Disease: 1993,1994,1996. J AM Water Works Assoc. $88: 66$
10.Hancock DD, Besser TE, Kinsel ML, Terr PI, Rice Dh, Peros M G. The Prevalence of Escherichia coli: $0157 . \mathrm{H} 7$ in dairy and beef cattle in Washington State. Epidermiol infect. 1994;113(2):199-207.

11.Husu JR. Epidemiology Studies on the Occurrence of Listeria monocytogenes in the feces of dairy cattle. JVet Med Ser. 1990;37:276282. Doi:10.1111/j.1439-0450.1990.tb01059.x

12.Jones P W. Health Hazards Associated with the handling of Animal Wastes. Vet Rec. 1980;106(1):4-7 